\title{
Nipple Reconstruction with Rolled Dermal Graft Support
}

\author{
Hui-Ling Chia ${ }^{1}$, Manzhi Wong ${ }^{2}$, Bien-Keem Tan ${ }^{2}$ \\ ${ }^{1}$ Department of Plastic, Reconstructive and Aesthetic Surgery, KK Women's and Children's Hospital, Singapore; ${ }^{2}$ Department of Plastic, \\ Reconstructive and Aesthetic Surgery, Singapore General Hospital, Singapore
}

Background Loss of nipple projection is a common problem following nipple reconstruction. The aim of this study was to demonstrate that the use of a tightly rolled dermal graft is effective in the long-term maintenance of nipple projection.

Methods Nipple reconstruction was performed using the $\mathrm{C}-\mathrm{V}$ flap technique. A dermal graft was harvested from the dog-ear portion of previous scars. The graft was rolled tightly into a compact cylinder and used to augment the nipple reconstruction. Postoperatively, stacked Allevyn dressing was used for protecting the nipple from compression for a minimum of two months. Nipple projection was measured at the time of surgery and at 12 months postoperatively.

Results Forty nipple reconstructions were performed using this technique. There were 19 transverse rectus abdominis musculocutaneous (TRAM) flaps, 10 latissimus dorsi (LD) flaps, and 11 tissue-expanded breast mounds. At one year, the mean projection was $0.80 \mathrm{~cm}$ (range, $0.62-1.22 \mathrm{~cm}$ ). The twelve-month average maintenance of nipple projection was $70.2 \%$ for the TRAM flap group, 76.3\% for the LD flap group, and 61.8\% for the tissue-expanded group. In two patients with previous irradiation of the reconstructed breasts, relatively poor maintenance of nipple projection was noted (45.7\%). No complications were noted, and all of the donor sites healed well primarily.

Conclusions Our results demonstrated that the use of a C-V flap with a tightly rolled dermal graft for nipple reconstruction improves the long-term maintenance of nipple projection. Its advantages include reproducibility, technical simplicity, cost-effectiveness, and minimal donor site morbidity.

Keywords Mammaplasty / Nipples / Dermis / Transplants
Correspondence: Bien-Keem Tan Department of Plastic, Reconstructive and Aesthetic Surgery Singapore General Hospital, Outram Road, Singapore 169608, Singapore Tel: $+65-6321-4686$ Fax: +65-6225-9340 E-mail: bienkeem@gmail.com
No potential conflict of interest relevant to this article was reported.

\section{INTRODUCTION}

Creating a natural nipple completes the aesthetics of breast reconstruction. Although a variety of techniques have been described, the long-term loss of nipple projection is disappointing to both patients and surgeons [1]. Nipple flattening is attributed to factors such as contractures within the reconstructed nipple and external pressure.

To overcome these factors, many surgeons have advocated the insertion of a graft, which acts as an internal strut in nipple reconstruction. The use of both autologous grafts and alloplastic materials has been widely reported. Rib or stacked auricular cartilage grafts produce long-lasting nipple projection but have the disadvantage of an extra donor site. Stacked dermal grafts incur 
less donor site morbidity, but the grafts, being non-rigid, are less effective in the maintenance of nipple projection.

Using a tightly rolled dermal graft, we can create a graft with axial rigidity, thereby achieving long-lasting nipple projection with minimal donor site morbidity.

\section{METHODS}

\section{Patients}

Between 2007 and 2011, 37 patients with an average age of 46 years (range, 27-66 years) underwent nipple reconstruction ( 34 unilateral and 3 bilateral cases). This was performed between 3 and 6 months after the completion of breast mound reconstruction. Nineteen patients underwent autologous breast reconstruction with the transverse rectus abdominis myocutaneous (TRAM) flap, and 10 patients had latissimus dorsi (LD) flap reconstruction with or without an implant. The remaining 11 patients had two-stage breast reconstruction using expanders and implants. The projection of the reconstructed nipple was measured using calipers at the time of surgery and at 12 months postoperatively.

\section{Surgical technique}

With the patient standing, the C-V flap [2] is marked using the contralateral breast as a reference for the nipple position and dimensions. In patients with skin paddles that have a relatively long transverse diameter, the $\mathrm{C}-\mathrm{V}$ flap is orientated vertically. This will shorten the horizontal width of the skin paddle and create a more circular nipple-areolar complex. Under local anesthesia, the "C" and " $V$ " flaps are raised at the superficial subcutaneous level to preserve the subdermal plexus (Fig. 1A). The tips of the "V" flaps are blunted to avoid skin tip necrosis, and the donor sites are closed with subdermal Monocryl 5-0 and interrupted Ethilon 5-0 sutures (Ethicon Inc., Somerville, NJ, USA). The "V" flaps are sutured together in a ying-yang fashion using
Ethilon 5-0 sutures.

An ellipse of the dermal graft, measuring approximately $3 \mathrm{~cm} \times$ $1.5 \mathrm{~cm}$, is harvested from the "dog ear" portion of a previous incision. If this is not available, the dermis can be harvested from skin adjacent to previous scars. This has the advantage of allowing concurrent revision of "dog ears" or breast mound excess. It is crucial to include only dermis and as little scar tissue as possible. The overlying epidermis is de-epithelialized very thinly with a size 10 blade to an approximate depth of 8/1,000th inch. The maximal thickness of the dermis is preserved, and fat is not included as it resorbs and interferes with grafting rolling. The donor site is closed primarily.

The dermal graft is wound tightly around an artery forceps clipped to one end, and interrupted Monocryl sutures are placed at intervals to prevent the graft from unraveling (Fig. 2). A suture is tied to one end of the graft, and the cylindrical graft is threaded in its erect position into the trough formed by the $\mathrm{V}$ flaps (Fig. 1B). To complete the reconstruction, the $\mathrm{C}$ flap is folded over and sutured to the $\mathrm{V}$ flaps by using Monocryl 6-0 sutures (Fig. 1C). Postoperatively, Allevyn (Smith \& Nephew, London, UK) sponge dressings are cut into doughnut shapes and stacked to protect the nipple from compression (Fig. 3). This splinting is continued for a minimum of 6 months to one year. Tattooing of the nipple-areolar complex is performed 3 to 6 months later.

\section{RESULTS}

Mean nipple projection at the time of surgery was $1.15 \mathrm{~cm}$ (range, $0.8-1.7 \mathrm{~cm}$ ). The average follow-up period was 25 months (range, 13-38 months). At one year, the mean projection was $0.80 \mathrm{~cm}$ (range, $0.62-1.22 \mathrm{~cm}$ ). Figs. 4, 5 show the postoperative results of patients who underwent nipple reconstruction using our technique following TRAM and LD reconstructions, respectively.

The maintenance of nipple projection is the percentage of projection at one year in relation to the projection immediately

\section{Fig. 1. Operative technique using rolled dermal graft}

Operative technique of nipple reconstruction using a rolled dermal graft. (A) The "C" and "V" flaps are elevated, and the "V" flap tips are blunted to prevent skin tip necrosis. (B) The rolled graft is threaded, in its erect position, into the trough formed by the $\mathrm{V}$ flaps. (C) The $\mathrm{C}$ flap is folded over and sutured to the $\mathrm{V}$ flaps.
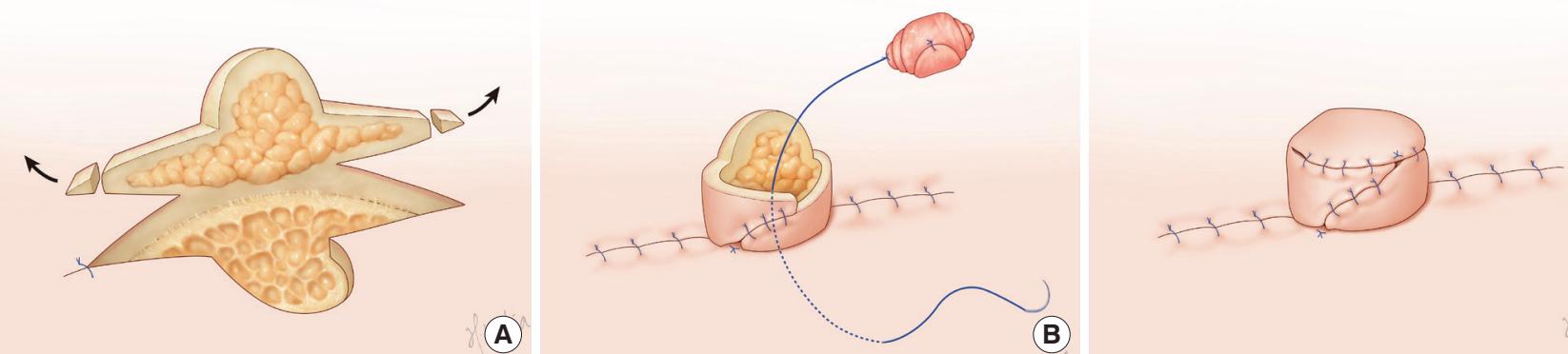


\section{Fig. 2. Rolling of the dermal graft}

(A) The dermal graft is rolled tightly, with the aid of an artery forceps clipped to one end of the graft. (B, C) Sutures are placed at intervals to keep the roll compact and to prevent it from unraveling. (D) Appearance of dermal graft after rolling.
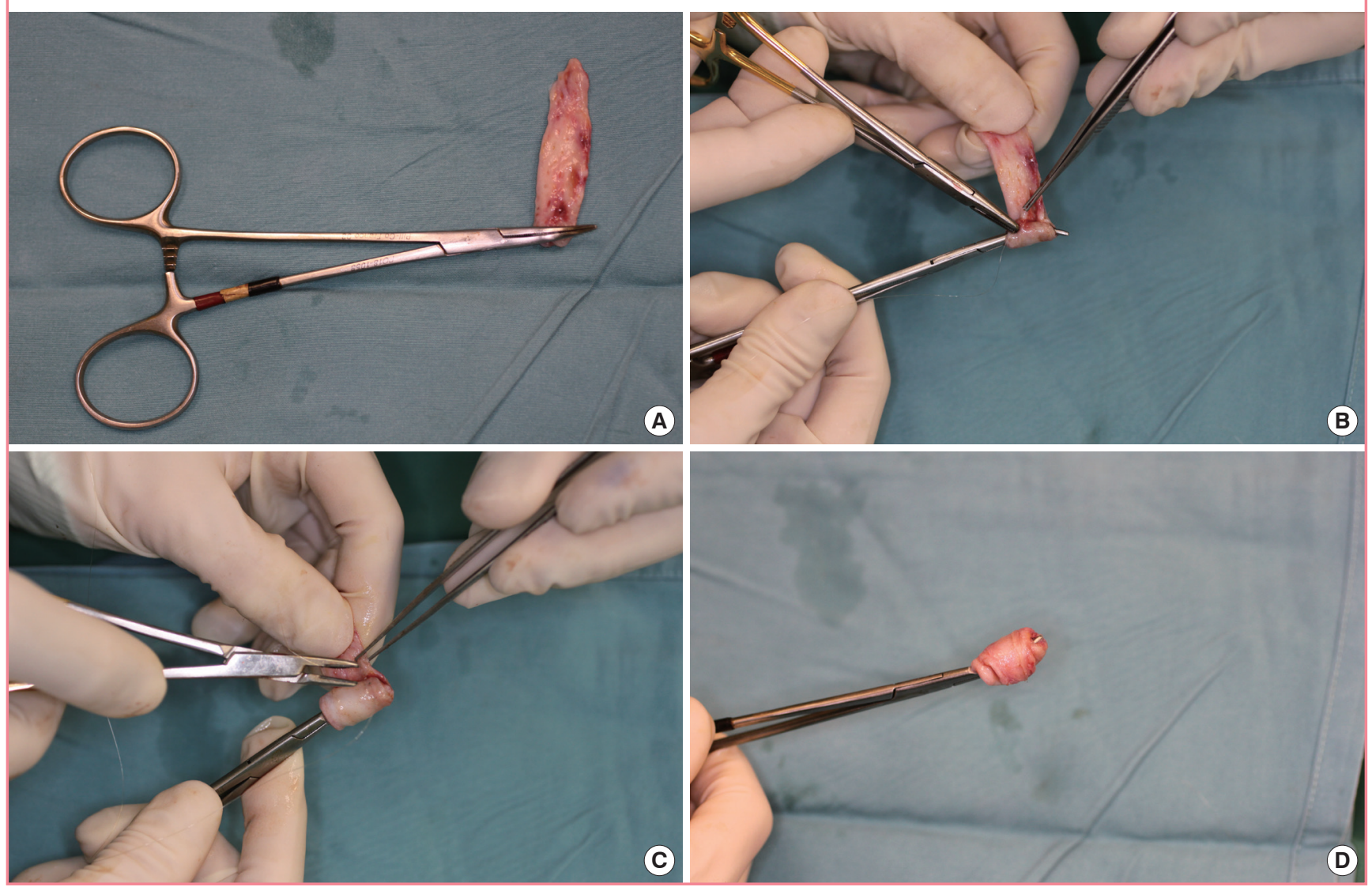

\section{Fig. 3. Postoperative stacked Allevyn sponge dressing}

Stacked Allevyn sponge dressing is used for protecting the nipple from compression.

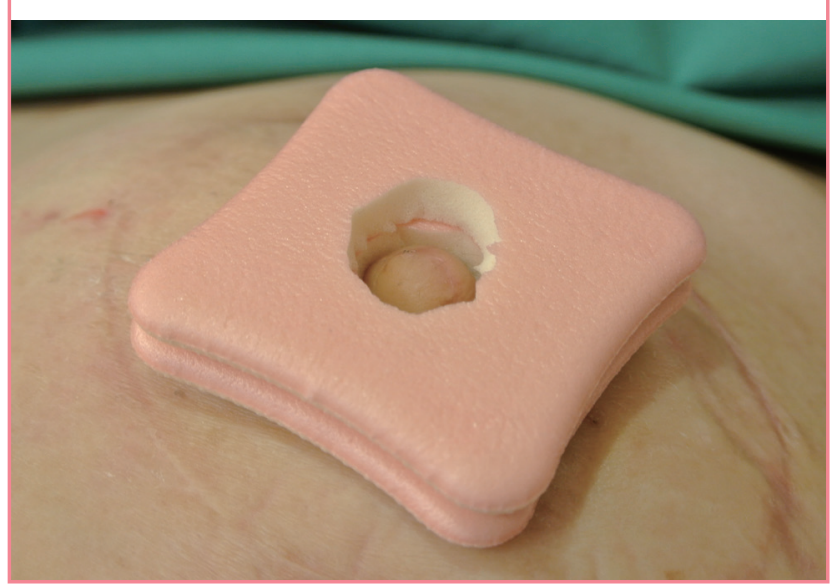

after the reconstruction. The average maintenance of nipple projection was $69.6 \%$ (70.2\% for the TRAM flap group, $76.3 \%$ for the LD flap group, and $61.8 \%$ for the tissue-expanded group). In four patients with previous irradiation of the reconstructed breasts, relatively poor maintenance of nipple projection was noted (45.7\%). In our series, no immediate or delayed postoperative complications, such as infection, extrusion of dermal graft, or donor site morbidity, were noted.

\section{DISCUSSION}

The maintenance of nipple projection can be as low as 30\% following nipple reconstruction [3]. A significant loss of projection occurs during the first 3 months, but it stabilizes by 1 year after reconstruction $[4,5]$. In the $\mathrm{C}-\mathrm{V}$ flap reconstruction, a central dead space that extends beyond the level of the skin into the subcutaneous layer is present when the $\mathrm{V}$ flaps are inset. We postulate that contracture within this deep trough contributes to the eventual nipple flattening.

The inclusion of a pillar of tissue as an internal strut to obliterate the dead space is a useful technique to resist these deformational forces. Valdatta et al. [6] demonstrated that in patients who underwent the $\mathrm{C}-\mathrm{V}$ flap reconstruction without a graft, the mean nipple projection at one year was $0.35 \mathrm{~cm}$ and the mean maintenance was $68 \%$. In our series, the mean projection at one year was $0.80 \mathrm{~cm}$ and the mean maintenance was $69.6 \%$. 


\section{Fig. 4. Patient with previous TRAM flap reconstruction}

Postoperative photos. (A) Immediate. (B) At 1 year. TRAM, transverse rectus abdominis musculocutaneous.
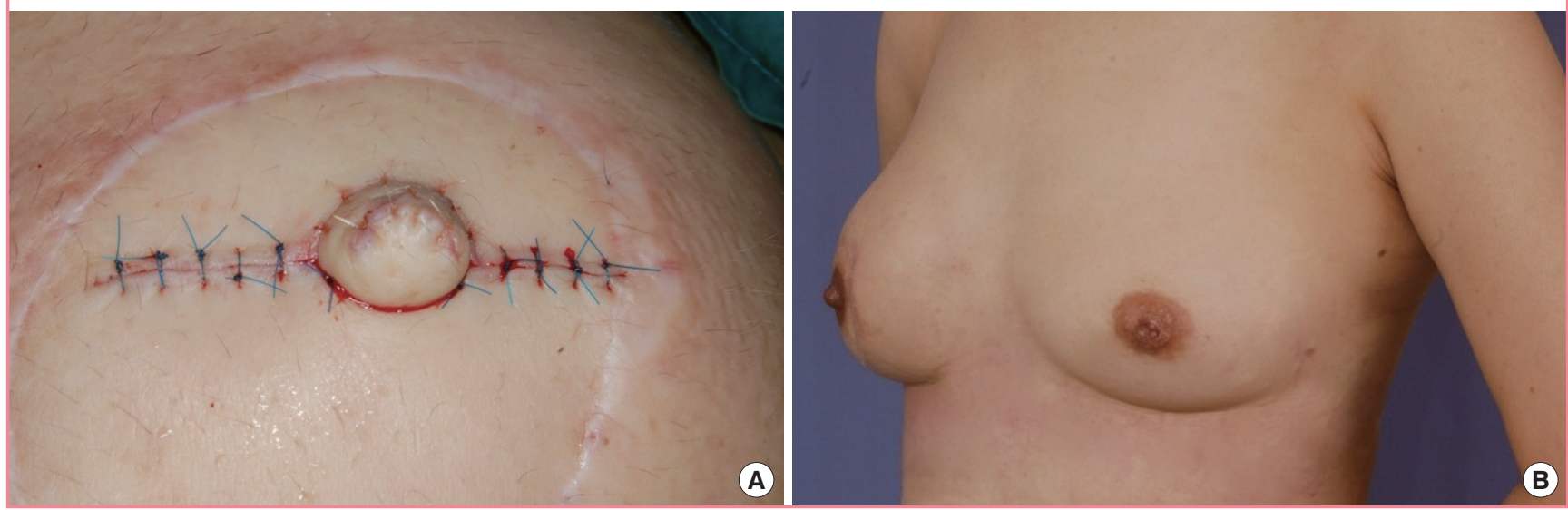

\section{Fig. 5. Patient with previous LD flap reconstruction}

Postoperative photograph of a patient who had previous latissimus dorsi (LD) flap reconstruction. (A) Anterior view. (B) Lateral view.
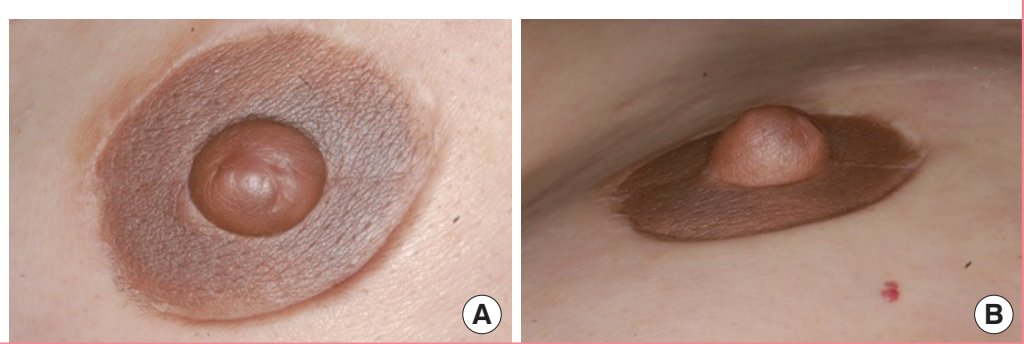

The use of dermal grafts has the advantage of allowing simultaneous scar revision, and as an autologous tissue, the risk of exposure and extrusion is very low. Long-term histologic evaluation of dermal grafts revealed degeneration of epithelial remnants with eventual transformation of the implanted dermis into well-vascularized fibrous tissue [7]. Eo et al. [8] described the use of stacked dermal grafts at the base of the nipple to improve projection. In our technique, the dermal graft is rolled tightly to form a compact cylinder, providing axial rigidity and immediately reinforcing the nipple shape and height.

Other grafts, such as auricular cartilage [9], rib cartilage [10], and toe pulp [11], have been described. The drawback of these options is the need for an extra donor site. An exception is the rib cartilage, which can be harvested and banked when the internal mammary vessels are used for the reconstruction of the breast. Although rib cartilage is superior in maintaining nipple projection, the excessive rigidity of the reconstructed nipple may not be desired. An alternative technique is the use of local deepithelialized dermal flaps, but these are limited by the quantity and quality of the local breast skin. Guerra et al. [10] reported 454 nipple reconstructions combining cartilage graft with a local arrow flap. Four percent of nipples in this study suffered cartilage graft loss due to exposure of the graft or ischemia of the flaps.
Synthetic materials used to augment nipple projection include polytetrafluoroethylene implants [12], artificial bone [13], and semipermanent injectable fillers, such as calcium hydroxylapatite [14]. Alloplastic materials are readily available and do not require a donor site. However, these options have an increased risk of extrusion and may predispose the patient to infections and wound-healing complications. Alloderm (LifeCell, Bridgewater, NJ, USA), an acellular human dermal substitute, was used as an internal strut with favorable results [15-17]. Our study has demonstrated that it is possible to improve the maintenance of nipple projection with an autologous dermal graft, without incurring the cost of Alloderm.

Although our results could not reach statistical significance, it supported previous findings that nipples reconstructed from the thicker dermis of latissimus dorsi skin islands were more resistant to contractures than those reconstructed from the thinner skin of the breast and abdomen [18]. In patients with previous adjuvant radiotherapy, poor wound healing and significant contracture of the reconstructed nipple were noted. In most cases, where the recipient vascular supply is robust and the graft is not excessively thick, a resorption rate of $25 \%$ to $30 \%$ [19] is predicted. A corresponding overcorrection should be performed to compensate for this sequelae. 


\section{REFERENCES}

1. Boccola MA, Savage J, Rozen WM, et al. Surgical correction and reconstruction of the nipple-areola complex: current review of techniques. J Reconstr Microsurg 2010;26:589-600.

2. Jones G, Bostwick III J. Nipple-areolar reconstruction. Oper Tech Plast Reconstr Surg 1994;1:35-8.

3. Shestak KC, Gabriel A, Landecker A, et al. Assessment of long-term nipple projection: a comparison of three techniques. Plast Reconstr Surg 2002;110:780-6.

4. Losken A, Mackay GJ, Bostwick J 3rd. Nipple reconstruction using the C-V flap technique: a long-term evaluation. Plast Reconstr Surg 2001;108:361-9.

5. Few JW, Marcus JR, Casas LA, et al. Long-term predictable nipple projection following reconstruction. Plast Reconstr Surg 1999; 104:1321-4.

6. Valdatta L, Montemurro P, Tamborini F, et al. Our experience of nipple reconstruction using the $\mathrm{C}-\mathrm{V}$ flap technique: 1 year evaluation. J Plast Reconstr Aesthet Surg 2009;62: 1293-8.

7. Davis RE, Guida RA, Cook TA. Autologous free dermal fat graft. Reconstruction of facial contour defects. Arch Otolaryngol Head Neck Surg 1995;121:95-100.

8. Eo S, Kim SS, Da Lio AL. Nipple reconstruction with C-v flap using dermofat graft. Ann Plast Surg 2007;58:137-40.

9. Tanabe HY, Tai Y, Kiyokawa K, et al. Nipple-areola reconstruction with a dermal-fat flap and rolled auricular cartilage. Plast Reconstr Surg 1997;100:431-8.

10. Guerra AB, Khoobehi K, Metzinger SE, et al. New technique for nipple areola reconstruction: arrow flap and rib cartilage graft for long-lasting nipple projection. Ann Plast Surg 2003;50:31-7.

11. Klatsky SA, Manson PN. Toe pulp free grafts in nipple reconstruction. Plast Reconstr Surg 1981;68:245-8.

12. Wong RK, Wichterman L, Parson SD. Skin sparing nipple reconstruction with polytetrafluoroethylene implant. Ann Plast Surg 2008;61:256-8.

13. Yanaga H. Nipple-areola reconstruction with a dermal-fat flap: technical improvement from rolled auricular cartilage to artificial bone. Plast Reconstr Surg 2003;112:1863-9.

14. Evans KK, Rasko Y, Lenert J, et al. The use of calcium hydroxylapatite for nipple projection after failed nipple-areolar reconstruction: early results. Ann Plast Surg 2005;55:25-9.

15. Garramone CE, Lam B. Use of AlloDerm in primary nipple reconstruction to improve long-term nipple projection. Plast Reconstr Surg 2007;119:1663-8.

16. Holton LH, Haerian H, Silverman RP, et al. Improving longterm projection in nipple reconstruction using human acellular dermal matrix: an animal model. Ann Plast Surg 2005; 55:304-9.

17. Chen WF, Barounis D, Kalimuthu R. A novel cost-saving approach to the use of acellular dermal matrix (AlloDerm) in postmastectomy breast and nipple reconstructions. Plast Reconstr Surg 2010;125:479-81.

18. Hammond DC, Khuthaila D, Kim J. The skate flap pursestring technique for nipple-areola complex reconstruction. Plast Reconstr Surg 2007;120:399-406.

19. Nahabedian MY. Secondary nipple reconstruction using local flaps and AlloDerm. Plast Reconstr Surg 2005;115:2056-61. 